\title{
Oct4 promotes cancer cell proliferation and migration and leads to poor prognosis associated with the survivin/STAT3 pathway in hepatocellular carcinoma
}

\author{
GANG WANG, HEMEI ZHOU, ZHIGANG GU, QUANGEN GAO and GENHAI SHEN \\ Department of Hepatobiliary Surgery, Wujiang No. 1 People's Hospital, Suzhou, Jiangsu 215200, P.R. China
}

Received October 20, 2017; Accepted May 31, 2018

DOI: $10.3892 /$ or.2018.6491

\begin{abstract}
Octamer-binding transcription factor 4 (Oct4) has been identified as a novel transcription factor associated with tumorigenesis, acquisition and maintenance of cancer stem cell characteristics and poor prognosis in tumors. However, the role of Oct4 in tumorigenesis and progression of hepatocellular carcinoma (HCC) has not yet been fully elucidated. In our present study, we observed that the Oct4 expression level was upregulated in HCC specimens as well as in different HCC cell lines. In in vitro experiments, decreased expression of Oct 4 by shRNA inhibited the viability and mobility of HCC cells. Furthermore, the loss of Oct4 inhibited HCC cell malignant progression accompanied by downregulated expression of the survivin/signal transducer and activator of transcription 3 (STAT3) pathway. Liver cancer patients with high expression of Oct 4 exhibited significantly shorter overall and disease-free survival. These findings demonstrated that Oct4 plays a vital role in the malignant progression of $\mathrm{HCC}$ cells through the survivin/STAT3 signaling pathway, and it may prove to be a novel biomarker associated with patient prognosis and survival.
\end{abstract}

\section{Introduction}

Hepatocellular carcinoma (HCC) is one of the most common malignant tumors worldwide, with relatively high incidence and mortality rates, particularly in Africa and Southeast Asia (1). Surgical resection remains the first choice for the treatment of early-stage HCC. However, despite a variety of comprehensive treatment strategies for patients with advanced liver cancer, the prognosis remains poor due to intrahepatic

Correspondence to: Dr Quangen Gao or Dr Genhai Shen, Department of Hepatobiliary Surgery, Wujiang No. 1 People's Hospital, 169 Gongyuan Road, Suzhou, Jiangsu 215200, P.R. China E-mail: wjyyqgg@sohu.com

E-mail: wjyy_sgh@163.com

Key words: hepatocellular carcinoma, octamer-binding transcription factor 4, malignant progression, poor prognosis, survivin/STAT3 pathway and distant metastasis. Metastasis and recurrence of $\mathrm{HCC}$ is a multistep, complex process involving numerous regulatory factors (2). The identification of novel biological regulating factors of HCC recurrence and metastasis is crucial for the targeted treatment of HCC patients.

Octamer-binding transcription factor 4 (Oct4) is a member of the POU transcription factor family that plays a key role in the development of almost all organisms (3). A number of studies have suggested that Oct4 may maintain the characteristics of cancer stem cells (4) and mediate the development of chemoresistance in tumor cells $(5,6)$. The aberrant expression of Oct 4 is implicated in the initiation and development of several malignant tumors, such as esophageal, gastric and breast, non-small-cell lung and prostate cancer and oral squamous cell carcinoma (7-13). However, little is known on the mechanisms underlying the involvement of Oct4 in the malignant progression of HCC.

Survivin is a new member of the apoptosis suppressor protein family. Survivin is only expressed in tumors and embryonic tissues, and is closely associated with differentiation, proliferation, cell cycle regulation, neovascularization, resistance to radiotherapy and chemotherapy, and infiltration and metastasis of tumor cells (14-19). In view of the abovementioned biological characteristics of survivin, it is likely to become a broad-spectrum cancer marker for diagnosis and clinical treatment.

The Janus kinase/signal transducers and activators of transcription (JAK/STAT) pathway represents a fast signal transduction pathway from the cytoplasm to the nucleus. Recent studies have demonstrated that the activation of the JAK/STAT signaling pathway, particularly of STAT3, has a major effect on cell growth, proliferation, transformation, resistance to chemotherapy-induced apoptosis and chemosensitivity in several tumors (20-24).

Oct4 has been found to exert important anti-apoptotic effects on embryonic stem cells under survival stress, and it has been suggested that these effects may be regulated by the survivin/STAT3 signaling pathway (25). Based on previous and the present findings, we hypothesized that Oct4 may be associated with malignant progression and poor prognosis in HCC through the survivin/STAT3 signaling pathway. By performing a series of in vitro and ex vivo experiments presented in this study, we demonstrated that Oct4 is involved in the malignant progression of HCC cells and poor prognosis 
of HCC patients, and its effects are likely mediated through the survivin/STAT3 signaling pathway.

\section{Materials and methods}

Patients and samples. Tissues from 53 patients with primary HCC treated at the Wujiang No. 1 People's Hospital (Jiangsu, China) between June 1, 2009 and December 31, 2011 were included in this study. These patients included 39 men and 14 women with a median age of 50 years (range, 36-67 years). The HCC tissues were obtained from patients who received hepatectomy and the diagnosis was pathologically confirmed. Long-term follow-up was conducted and the median time was 39.0 months (range, 5-60.0 months). The study protocol was approved by the Ethics Committee of Wujiang No. 1 People's Hospital and all patients signed a written informed consent form.

Cell lines and cell culture. The human normal liver cell line LO2 and the HCC cell lines SMMC-7721, Huh-7, MHCC97H, PLC/PRF/5 and Hep3B were purchased from the Cell Bank of Type Culture Collection of the Chinese Academy of Sciences (Shanghai, China). All cells were routinely maintained as a monolayer in high-glucose Dulbecco's modified Eagle's medium (DMEM) supplemented with 10\% fetal bovine serum (FBS), $100 \mathrm{mg} / \mathrm{ml}$ streptomycin and $100 \mathrm{IU} / \mathrm{ml}$ penicillin G.

Immunohistochemical staining. All patient tissues were obtained from the specimens resected during surgery. Paraffin-embedded consecutive sections $(4-\mu \mathrm{m})$ were examined for Oct4, survivin and phosphorylated STAT3 (pSTAT3) expression. The primary antibodies were as follows: Mouse anti-human Oct4 (dilution 1:100; cat. no. sc-5279; Santa Cruz Biotechnology, Inc., Santa Cruz, CA, USA), rabbit anti-human survivin (71G4B7) (dilution 1:200; cat. no. 2808) and p-STAT3 (Tyr705; dilution 1:100; cat. no. 9145; both from Cell Signaling Technology, Inc., Danvers, MA, USA). The MaxVision ${ }^{\text {TM }}$ HRP-polymer anti-mouse/rabbit IHC kit (Kit-5010; Fuzhou Maixin Biotechnology Development, Co., Ltd., Fuzhou, China) was used. The evaluation criteria included the number and proportion of positive cells. Five random high-power fields were examined and the evaluation of staining reaction was performed with the immunoreactive score (26). A score of $>4$ was considered to indicate high expression.

Reverse transcription-quantitative polymerase chain reaction (RT-qPCR). Total RNA was extracted from tissue samples and cell lines using TRIzol (Invitrogen; Thermo Fisher Scientific, Inc., Waltham, MA, USA). The RNA concentration was assessed using a UV spectrophotometer (Ultrospec 2,100 pro; Amersham; GE Healthcare, Chicago, IL, USA). RNA $(0.8 \mu \mathrm{g})$ was reversely transcribed into cDNA using the PrimeScript RT reagent kit (Takara Bio, Inc., Otsu, Japan) according to the manufacturer's instructions. The qPCR was performed using SYBR ${ }^{\circledR}$ Premix Ex Taq (Takara Bio, Inc.) on the Applied Biosystems 7500 Real-time PCR System (Applied Biosystems; Thermo Fisher Scientific, Inc.), with GAPDH used as an internal control. The primers used were as follows: Oct4 forward, 5'-AGGGCTTCTCCTTCTGGGTCT-3' and reverse, 5'-TGAGAAAGGAGACCCAGCAG-3'; GAPDH forward,
5'-TGACTTCAACAGCGACACCCA-3' and reverse, 5'-CAC CCTGTTGCTGTAGCCAAA-3'. The pre-amplification PCR was performed at one cycle $95^{\circ} \mathrm{C}$ for $5 \mathrm{~min}, 30$ cycles at $95^{\circ} \mathrm{C}$ for $30 \mathrm{sec}, 55^{\circ} \mathrm{C}$ for $30 \mathrm{sec}$ and then $72^{\circ} \mathrm{C}$ for $30 \mathrm{sec}$. The product was stored at $4^{\circ} \mathrm{C}$ until needed. All reactions were performed in triplicate and the relative expression of Oct 4 mRNA was calculated using the $2^{-\Delta \Delta \mathrm{Cq}}$ method (24).

Construction and transfection of shRNA vectors. The Oct4-shRNA and the control vector were purchased from Santa Cruz Biotechnology, Inc. (sc-36123-SH). HCC cells were transfected with shRNA vectors at a concentration of $4 \mu \mathrm{g} / 10^{5}$ cells using the Lipofectamine 2000 transfection reagent (Invitrogen Corp., Shanghai, China). Following routine culture for $48 \mathrm{~h}$ after transfection, the cells were harvested for further experiments.

Cell viability assay. The proliferation of Hep3B cells with different pretreatment was detected using the MTT assay. Hep3B cells were cultured in 96-well plates at a density of 5,000 cells/well and transfected with shRNA vector as aforementioned. MTT $(5 \mathrm{mg} / \mathrm{ml})$ was added into each well after transfection for $48 \mathrm{~h}$ and continuously incubated for $4 \mathrm{~h}$. Finally, $150 \mu 1$ dimethyl sulfoxide (DMSO) was added into each well and the absorbance was measured at $490 \mathrm{~nm}$ using a microplate reader.

Soft agar colony formation assay. A soft agar colony formation assay was used to evaluate cell growth capacity. HCC cells were collected and counted after transfection, and $1 \times 10^{4}$ cells were mixed with agar solution $(0.6 \%)$ in high-glucose DMEM containing $20 \%$ fetal bovine serum and layered on top of an agar layer (1.2\%) in 6-well plates. Cells were continuously incubated for 2-3 weeks in a 5\% $\mathrm{CO}_{2}$ humidified incubator at $37^{\circ} \mathrm{C}$ until colonies were formed. High-glucose DMEM supplemented with $10 \%$ FBS was added to the culture every 3-4 days. Each colony was defined as a spheroid containing $>50$ cells.

Cell mobility assays. The Transwell chamber assay (pore size $8 \mu \mathrm{m}$; EMD Millipore, Billerica, MA, USA) was used to evaluate the mobility of HCC cells according to the manufacturer's instructions. The cell migration assay was performed with an $8-\mu \mathrm{m}$ Transwell chamber and the cell invasion assay was performed with a Transwell chamber pre-coated with Matrigel (1:6; BD Biosciences, Franklin, Lakes, NJ, USA). HCC cells were collected and counted after transfection for $48 \mathrm{~h}$, and $5 \times 10^{4}$ cells were seeded into the upper chamber, whereas DMEM with 20\% FBS was placed into the lower chamber. After incubation for $24 \mathrm{~h}, \mathrm{HCC}$ cells that migrated through the membranes were fixed using $90 \%$ ethanol and stained with crystal violet solution $(0.1 \%)$. Five random fields were selected and the cells were counted under a microscope.

Western blotting. HCC cells were collected and counted after transfection for $48 \mathrm{~h}$. Approximately $1 \times 10^{6}$ cells were lysed using RIPA lysis buffer (cat. no. P0013C; Beyotime Institute of Biotechnology, Jiangsu, China). The enhanced BCA protein assay kit (cat. no. P0010S; Beyotime Institute of Biotechnology) was used to quantify protein concentration. The primary antibodies 
A

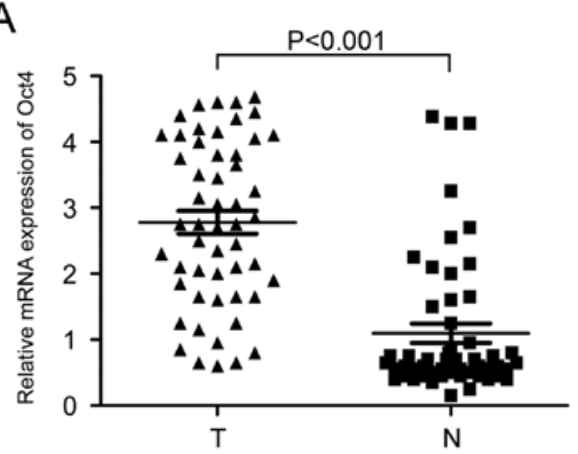

B
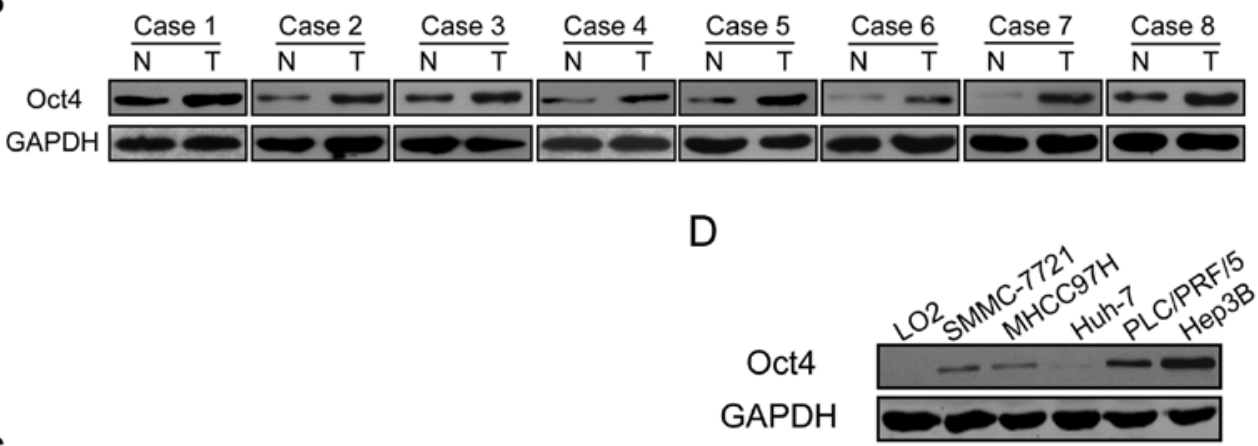

C
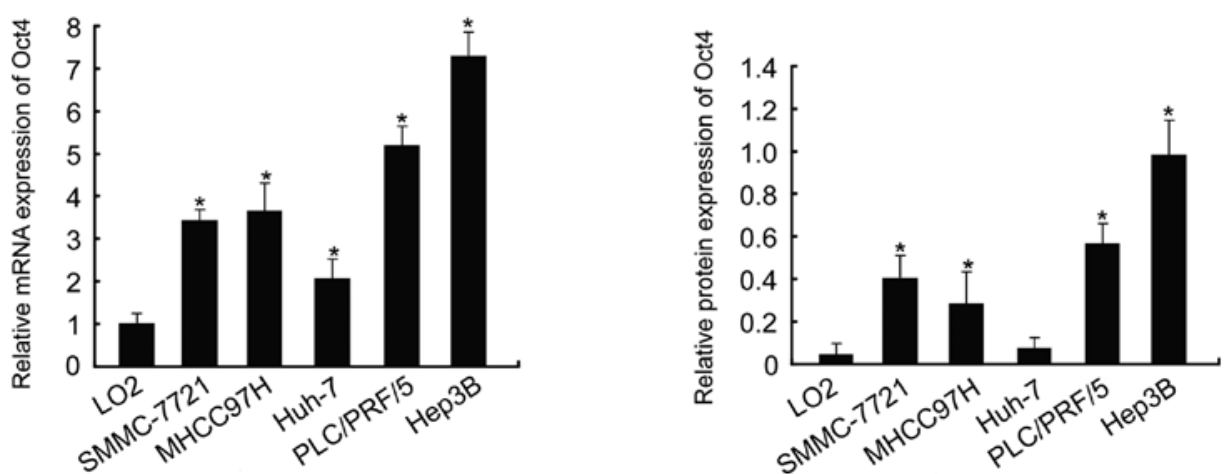

Figure 1. Oct4 is overexpressed in HCC samples and cell lines. (A) RT-qPCR was applied to examine Oct4 expression in HCC samples and adjacent normal liver tissues $(\mathrm{n}=53, \mathrm{P}<0.001)$. The upper and lower horizontal lines indicate standard deviation. The middle horizontal line indicates the mean value. (B) Oct 4 protein expression in HCC tissues was also assessed by western blotting $(\mathrm{n}=8)$. (C) The mRNA expression of Oct4 in HCC cells and normal liver cells was evaluated by RT-qPCR ("P<0.05). (D) The protein expression of Oct4 in HCC cells and normal liver cells was examined by western blotting ( $\left.{ }^{*} \mathrm{P}<0.05\right)$. Oct4, octamer-binding transcription factor 4; HCC, hepatocellular carcinoma; RT-qPCR, reverse transcription-quantitative polymerase chain reaction.

were as follows: Anti-survivin (71G4B7) (dilution 1:1,000; cat. no. 2808; Cell Signaling Technology), Oct4 (dilution 1:500; cat. no. sc-5279; Santa Cruz Biotechnology), STAT3 (124H6) (dilution 1:1,000; cat. no. 9139) and pSTAT3 (Tyr705) (1:1,000; cat. no. 9145; both from Cell Signaling Technology). The results were visualized using an enhanced chemiluminescence reagent (PerkinElmer, Inc., Shanghai, China). The resultant film images were analyzed by Quantity One analysis software (Bio-Rad Laboratories, Hercules, CA, USA).

Immunofluorescence staining. HCC cells transfected with Oct4-shRNA were grown on coverslips in 6-well dishes. After transfection for $48 \mathrm{~h}$, the HCC cells were rinsed with phosphate-buffered saline (PBS) twice, then fixed with $15 \%$ formaldehyde and permeabilized with $1 \%$ Triton X-100. Next, the cells were blocked by incubation with non-immune animal serum at room temperature for $1 \mathrm{~h}$, followed by incubation with one of the primary antibodies (dilution $1: 200$ ) at $4^{\circ} \mathrm{C}$ overnight. The following day, the cells were washed and incubated in the dark for $1 \mathrm{~h}$ with Alexa Fluor Cy3-conjungated goat anti-mouse (cat. no. A0521), Alexa Fluor 488-conjungated goat anti-rat (cat. no. A0428) and Alexa Fluor 647-conjungated goat anti-rabbit IgG secondary antibodies (dilution 1:400; cat. no. A0468) (Beyotime Institute of Biotechnology) at room temperature, and then co-stained with DAPI $(1 \mu \mathrm{g} / \mathrm{ml}$; Sigma-Aldrich; Merck KGaA, Darmstadt, Germany). Images of the immunostained cells were obtained using a fluorescence microscope (magnification, x200).

Statistical analysis. All presented data are expressed as the median \pm standard deviation and were compared with the Student's t-test or one-way analysis of variance (ANOVA) using SPSS software, version 19.0 for Windows (SPSS, Inc., Chicago, IL, USA). Multigroup comparisons of the means 
Table I. Associations of Oct expression with clinicopathological features in 53 HCC patients.

\begin{tabular}{lcccc}
\hline Variables & Total $(\mathrm{n}=53)$ & Oct4-high $(\mathrm{n}=36)$ & Oct4-low $(\mathrm{n}=17)$ & P-value \\
\hline Age $(\leq 50 />50$ years) & $16 / 37$ & $11 / 25$ & $5 / 12$ & 0.933 \\
Sex (male/female) & $39 / 14$ & $28 / 8$ & $11 / 6$ & 0.314 \\
Hepatitis $(\mathrm{HBV} / \mathrm{HCV} / \mathrm{none})$ & $31 / 9 / 13$ & $21 / 6 / 9$ & $10 / 3 / 4$ & 0.991 \\
Serum AFP ( $\leq 400 />400 \mathrm{ng} / \mathrm{ml})$ & $25 / 28$ & $15 / 21$ & $10 / 7$ & 0.243 \\
Liver cirrhosis (yes/no) & $43 / 10$ & $30 / 6$ & $13 / 4$ & 0.551 \\
BCLC stage $(0-\mathrm{A} / \mathrm{B} / \mathrm{C})$ & $38 / 9 / 6$ & $24 / 7 / 5$ & $14 / 2 / 1$ & 0.484 \\
Tumor size ( $\leq 5.0 />5.0 \mathrm{~cm})$ & $26 / 27$ & $14 / 22$ & $12 / 5$ & 0.031 \\
Tumor number (single/multiple) & $37 / 16$ & $23 / 13$ & $14 / 3$ & 0.172 \\
TNM stage $(\mathrm{I} / \mathrm{II} / \mathrm{III})$ & $18 / 23 / 12$ & $8 / 19 / 9$ & $10 / 4 / 3$ & 0.029 \\
Tumor encapsulation (yes/no) & $28 / 25$ & $16 / 20$ & $12 / 5$ & 0.075 \\
Vascular invasion $^{\mathrm{b}}$ (yes/no) & $33 / 20$ & $26 / 10$ & $6 / 11$ & 0.010
\end{tabular}

${ }^{a}$ The sixth edition of the International Union Against Cancer (UICC) tumor-node-metastasis (TNM) staging system (2002). ${ }^{\mathrm{b} D e f i n e d}$ by findings on final pathological analysis. Oct4, octamer-binding transcription factor 4; HCC, hepatocellular carcinoma; AFP, $\alpha$-fetoprotein; HBV, hepatitis B virus; $\mathrm{HCV}$, hepatitis $\mathrm{C}$ virus.

were carried out by ANOVA test with post hoc contrasts by Student-Newman-Keuls test. The association between the Oct4 expression level and the clinicopathological factors was analyzed using Pearson's $\chi^{2}$ test. Survival time analysis was performed using the Kaplan-Meier survival method. $\mathrm{P}<0.05$ in the univariate analyses were further tested using the multivariate Cox proportional hazards model. $\mathrm{P}<0.05$ was considered to indicate statistically significant differences.

\section{Results}

Oct4 is overexpressed in HCC tissues and cell lines. In the present study, Oct4 mRNA expression was determined in HCC tissues and adjacent liver tissues using RT-qPCR. As shown in Fig. 1A, the relative expression levels of Oct4 were higher in HCC tissues compared with those in adjacent normal liver tissues $(n=53, P<0.001)$. Furthermore, the expression levels of the Oct4 protein were higher in tumors compared with those in the corresponding non-malignant liver tissues (Fig. 1B, n=8).

In addition, Oct4 expression was assessed in $\mathrm{HCC}$ cell lines (SMMC-7721, Huh-7, MHCC97H, PLC/PRF/5 and Hep3B) and in the normal liver cell line LO2. Similar to the expression pattern in $\mathrm{HCC}$ tissues, the expression of Oct 4 at the mRNA and protein levels was upregulated in HCC cell lines compared with normal liver cells (Fig. $1 C$ and D; $\mathrm{P}<0.05$ ). We also found that Oct4 was expressed at different levels in the HCC cell lines. These data revealed that the aberrant expression of Oct4 may affect HCC initiation and progression. Hep3B cells, which exhibited the highest expression of Oct4, were selected for subsequent experiments.

The loss of Oct4 inhibits HCC cell viability and mobility in vitro. We evaluated three time-points (24, 48 and $72 \mathrm{~h}$ ) following transfection of Hep3B cells with Oct4-shRNA. The results revealed that Hep3B cells transfected with Oct4-shRNA exhibited significantly decreased viability compared with those transfected with Ctrl-shRNA (Fig. 2A;
$\mathrm{P}<0.05)$. Furthermore, we also evaluated the rate of colony formation of Hep3B cells at 2 weeks after transfection. Our results revealed that Hep3B cells transfected with Oct4-shRNA formed fewer colonies compared with those transfected with Ctrl-shRNA (Fig. 2B, P<0.05).

To assess the effect of Oct4-shRNA on cell motility, Hep3B cells underwent migration and invasion assays following transfection. The results confirmed that the number of migratory and invasive cells in the Oct4-shRNA transfected Hep3B cell group was markedly decreased compared with that in the Ctrl-shRNA group (Fig. $2 \mathrm{C}, \mathrm{P}<0.05$ ). These results revealed that the downregulation of Oct 4 contributed to the inhibition of migration and invasion of Hep3B cells in vitro. Therefore, Oct4 may play a key role in the regulation of Hep3B cell motility, including invasion and metastasis.

Depletion of Oct4 affects the survivin/STAT3 signaling pathway. In this study, western blotting and cell immunofluorescence assays were used to investigate Oct4-related signaling pathway proteins. The results of the immunofluorescence assay revealed that Oct4-depleted HCC cells exhibited notably decreased survivin and p-STAT3 expression levels at the same time (Fig. 3). Western blot analysis confirmed these results. The protein levels of survivin and p-STAT3 were decreased following downregulation of Oct4 (Fig. 3), suggesting that Oct 4 depletion adversely affects the activation of the survivin/STAT3 signaling pathway, which may play an important role in the malignant progression of HCC cells.

Associations of Oct4 expression in HCC with clinicopathological factors. Oct4 is mainly expressed in the nuclei and survivin/STAT3 are mainly distributed in the cytoplasm of tumor cells (Fig. 4). A score of $>4$ was considered to indicate high expression. The 53 patients were divided into two groups, namely the Oct4-high and Oct4-low groups. The clinicopathological variables in these two groups are compared in Table I. Our results revealed that the Oct4-high subtype was 
A

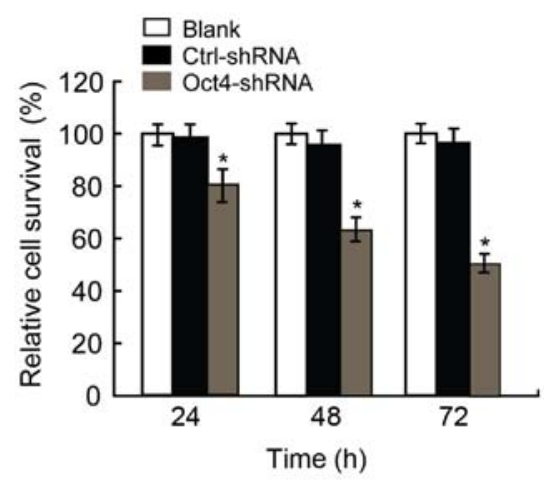

B

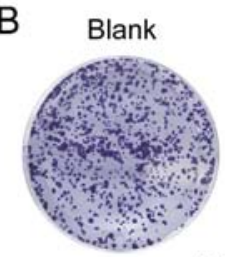

Ctrl-shRNA
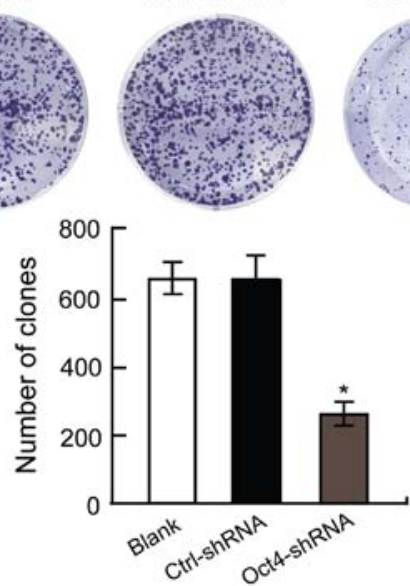

C
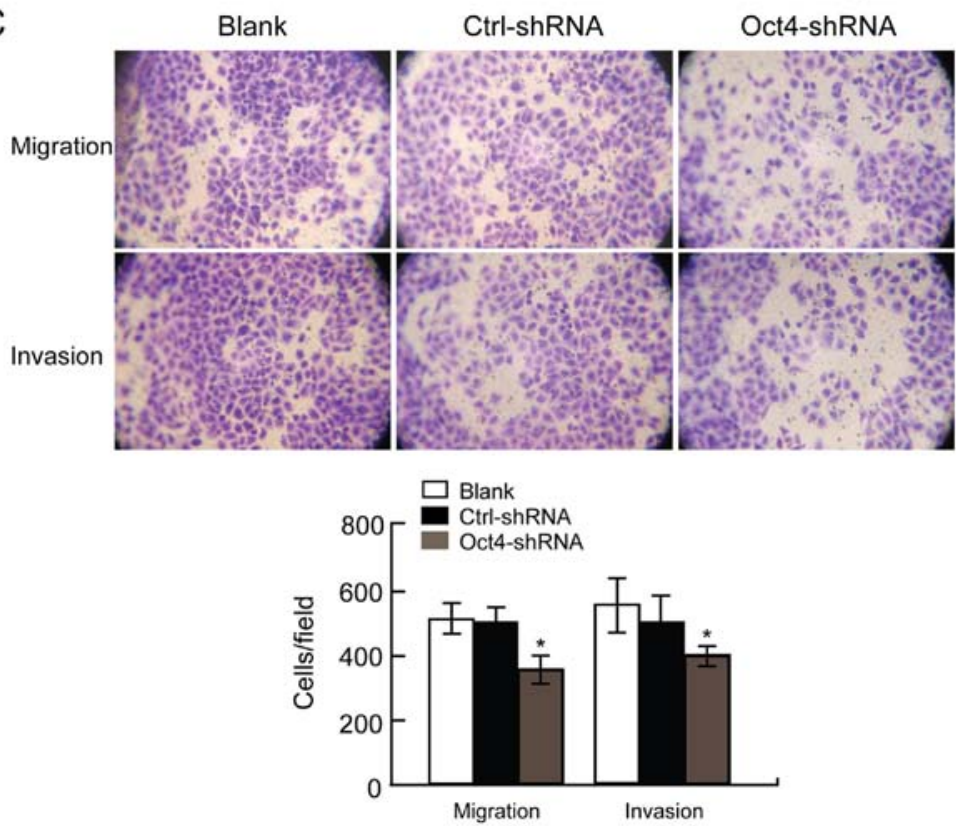

Figure 2. Downregulation of Oct4 significantly inhibits viability, proliferation and mobility of HCC cells in vitro. (A) Cell viability was analyzed by MTT assay. Hep3B cells were transfected with Oct4-shRNA for 24,48 and $72 \mathrm{~h}$, which led to significant inhibition of cell viability compared with the blank and Ctrl-shRNA groups ( $\mathrm{P}<0.05)$. (B) The proliferation ability of Hep3B cells transfected with Oct4-shRNA was assessed by soft agar colony formation assay $\left({ }^{*} \mathrm{P}<0.05\right)$. (C) The migration and invasion abilities of Hep3B cells transfected with Oct4-shRNA were assessed using Transwell and Matrigel assays, respectively. Data are presented as the mean \pm standard deviation, as derived from three independent experiments. ${ }^{*} \mathrm{P}<0.05$ vs. the other groups. Magnification, $\mathrm{x} 100$. Oct4, octamer-binding transcription factor 4; HCC, hepatocellular carcinoma.

Table II. Association of Oct4 with survivin/pSTAT3 expression in $53 \mathrm{HCC}$ patients.

\begin{tabular}{lrrrrr}
\hline & \multicolumn{2}{c}{ Oct4 } & & \\
\cline { 2 - 3 } & High & Low & & r & P-value \\
\hline Survivin & & & & \\
High & 26 & 7 & 0.299 & 0.031 \\
Low & 10 & 10 & & \\
pSTAT3 & & & & \\
High & 24 & 5 & 0.349 & 0.012 \\
Low & 12 & 12 & & \\
\hline
\end{tabular}

Oct4, octamer-binding transcription factor 4; HCC, hepatocellular carcinoma. STAT3, survivin/signal transducer and activator of transcription 3; pSTAT3, phosphorylated STAT3. significantly correlated with tumor size $(\mathrm{P}=0.031)$, TNM stage $(\mathrm{P}=0.029)$ and vascular invasion $(\mathrm{P}=0.010)$. The associations are detailed in Table II and Oct4 expression was found to be positively correlated with survivin $(\mathrm{r}=0.299, \mathrm{P}=0.031)$ and pSTAT3 expression $(\mathrm{r}=0.349, \mathrm{P}=0.012)$.

Oct4-high HCC subtype has a poor prognosis. As shown in Fig. 5, HCC patients with Oct4-high tumors had a significantly shorter overall survival time $(\mathrm{P}=0.023$, Fig. 5) and recurrence-free survival time ( $\mathrm{P}=0.0182$, Fig. 5) compared with those with Oct4-low tumors. Through univariate analysis, 5 clinicopathological variables were selected to be further investigated by multivariate analysis (Table III). The data revealed that Oct 4 overexpression was one of the potential independent prognostic factors for overall and recurrence-free survival, although not as significant as were advanced TNM stage and vascular invasion (Table III). 
A

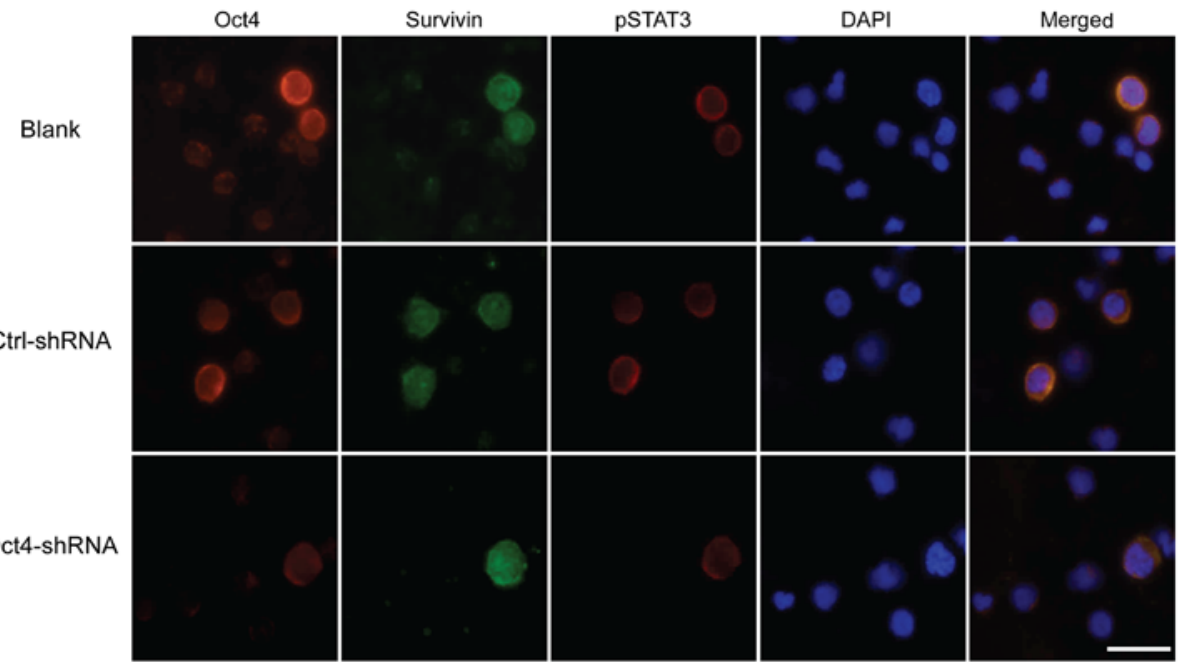

B
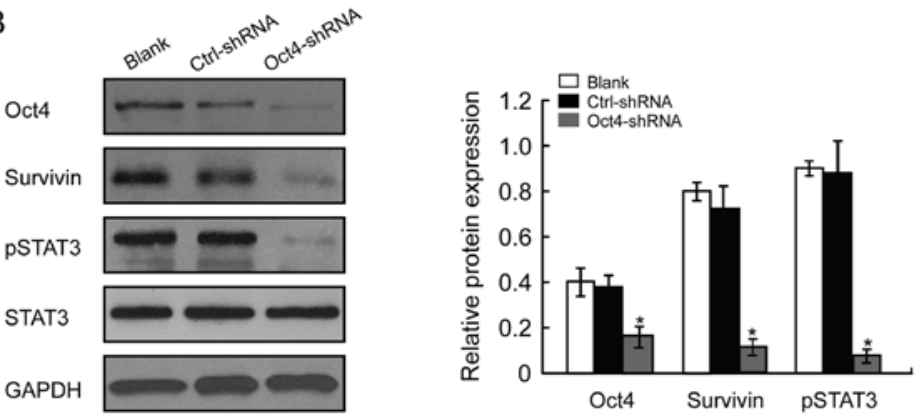

Figure 3. Decreased expression of Oct4 suppresses survivin/STAT3 signaling pathway in HCC cells. (A) Oct4, survivin and p-STAT3 expression were detected using immunofluorescence. Scale bar, $50 \mu \mathrm{m}$. (B) The protein expression of Oct4, survivin, STAT3 and p-STAT3 in Hep3B cells transfected with Oct4-shRNA were evaluated using western blot analysis (" $\mathrm{P}<0.05$ vs. the other groups). Oct4, octamer-binding transcription factor 4; STAT3, signal transducer and activator of transcription 3; HCC, hepatocellular carcinoma.
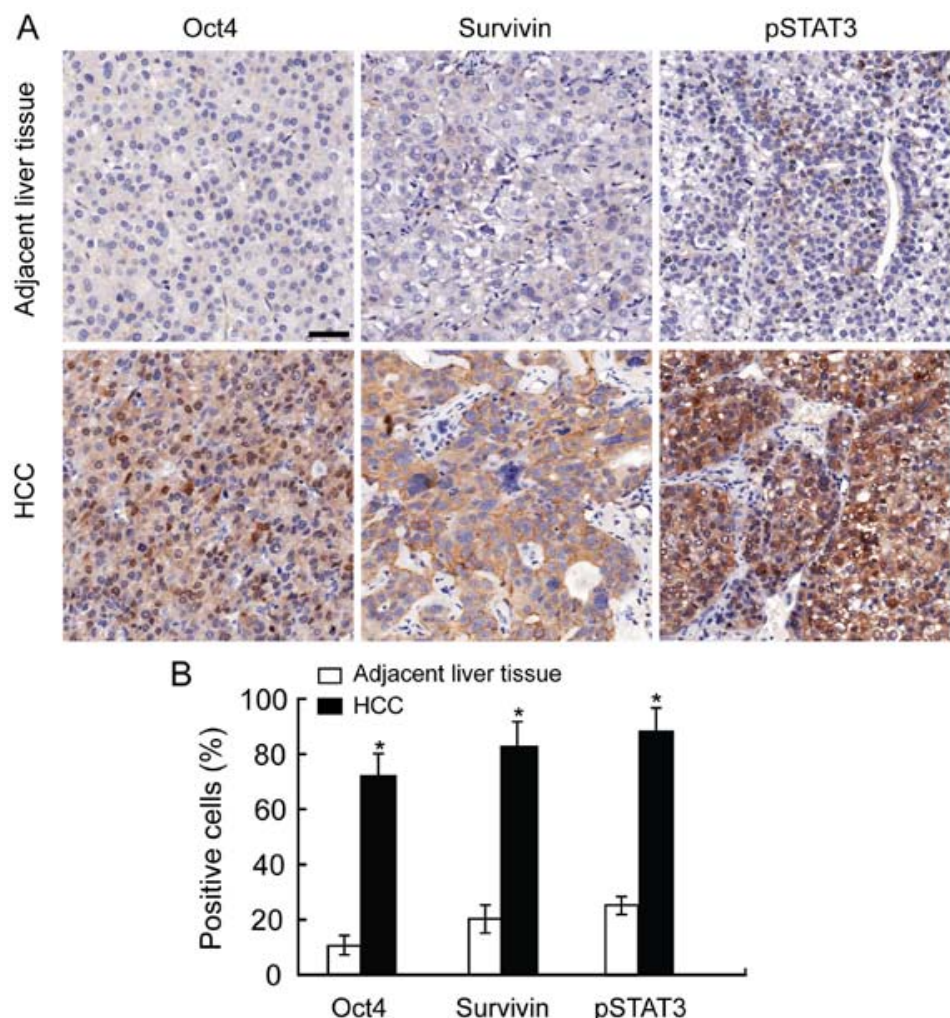

Figure 4. Oct4 and survivin/STAT3 expression change in HCC tissues. (A) Representative immunohistochemical images of paraffin-embedded sections of human HCC tissues and adjacent normal liver tissues for detection of Oct4, survivin and p-STAT3. PBS instead of the primary antibodies was used as a negative control. The positive cells were counted within 10 high-power fields by two independent researchers. Scale bar, $50 \mu \mathrm{m}$ ("P<0.05 vs. the other groups). (B) Quantification of A. Oct4, octamer-binding transcription factor 4; STAT3, signal transducer and activator of transcription 3; HCC, hepatocellular carcinoma; PBS, phosphate-buffered saline. 

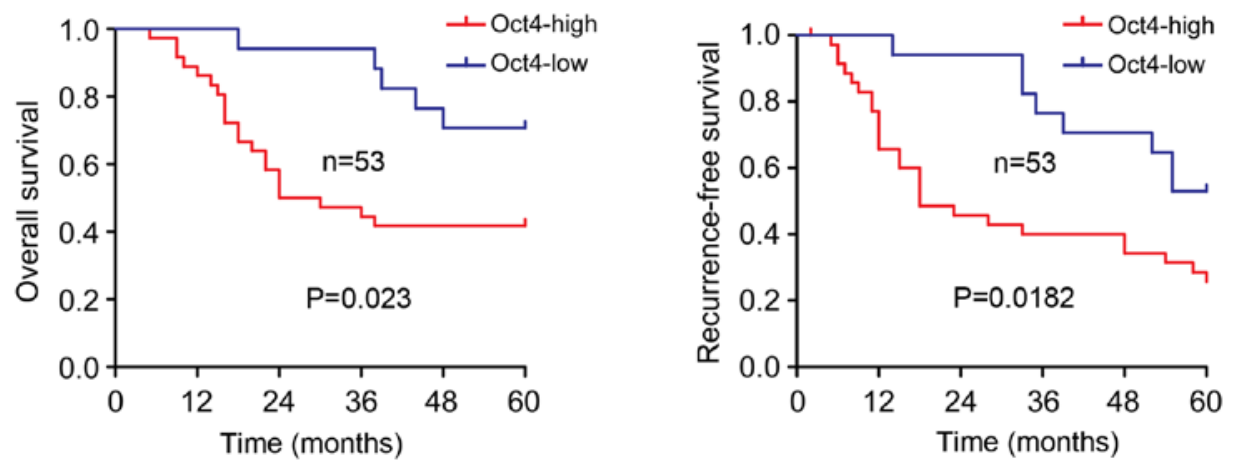

Figure 5. Upregulation of Oct4 is associated with poor prognosis in HCC patients. Overall survival and disease-free survival rates based on Oct4 expression in 53 patients who underwent hepatectomy for HCC. Upregulated expression of Oct 4 was associated with poorer overall and recurrence-free survival rates ( $\mathrm{P}=0.023$ and $\mathrm{P}=0.0182$, respectively). Oct4, octamer-binding transcription factor 4; HCC, hepatocellular carcinoma.

Table III. Univariate and multivariate analyses of the factors associated with survival and recurrence in 53 HCC patients.

\begin{tabular}{|c|c|c|c|c|c|c|}
\hline \multirow[b]{3}{*}{ Factors } & \multicolumn{3}{|c|}{ OS } & \multicolumn{3}{|c|}{ RFS } \\
\hline & \multirow{2}{*}{$\frac{\text { Univariate }}{\text { P-value }}$} & \multicolumn{2}{|c|}{ Multivariate } & \multirow{2}{*}{$\frac{\text { Univariate }}{\text { P-value }}$} & \multicolumn{2}{|c|}{ Multivariate } \\
\hline & & $\mathrm{HR}(95 \% \mathrm{CI})$ & P-value & & $\mathrm{HR}(95 \% \mathrm{CI})$ & P-value \\
\hline $\begin{array}{l}\text { Age } \\
(\leq 50 \text { vs. }>50 \text { years })\end{array}$ & 0.564 & & NA & 0.961 & & NA \\
\hline $\begin{array}{l}\text { Sex } \\
\text { (male vs. female) }\end{array}$ & 0.699 & & NA & 0.963 & & NA \\
\hline $\begin{array}{l}\text { Hepatitis history } \\
\text { (Yes vs. no) }\end{array}$ & 0.173 & & NA & 0.278 & & NA \\
\hline $\begin{array}{l}\text { Serum AFP } \\
\leq 400 \mathrm{vs} .>400 \mathrm{ng} / \mathrm{ml}\end{array}$ & 0.076 & & NA & 0.197 & & NA \\
\hline $\begin{array}{l}\text { Liver cirrhosis } \\
\text { (Yes vs. no) }\end{array}$ & 0.189 & & NA & 0.223 & & NA \\
\hline $\begin{array}{l}\text { BCLC stage } \\
(0-A \text { vs. B-C) }\end{array}$ & 0.019 & $\begin{array}{c}1.027 \\
(0.427-2.469)\end{array}$ & 0.953 & 0.001 & $\begin{array}{c}1.423 \\
(0.645-3.177)\end{array}$ & 0.378 \\
\hline $\begin{array}{l}\text { Tumor size } \\
(\leq 5.0 \mathrm{vs} .>5.0 \mathrm{~cm})\end{array}$ & 0.086 & & NA & 0.129 & & NA \\
\hline $\begin{array}{l}\text { Tumor number } \\
\text { (single vs. multiple) }\end{array}$ & 0.063 & & NA & 0.074 & & NA \\
\hline $\begin{array}{l}\text { TNM stage } \\
\text { (I vs. II-III) }\end{array}$ & $<0.001$ & $\begin{array}{c}4.665 \\
(1.068-20.376)\end{array}$ & 0.041 & $<0.001$ & $\begin{array}{c}3.018 \\
(1.075-8.472)\end{array}$ & 0.036 \\
\hline $\begin{array}{l}\text { Tumor encapsulation } \\
\text { (yes vs. no) }\end{array}$ & 0.001 & $\begin{array}{c}0.554 \\
(0.222-1.381)\end{array}$ & 0.205 & 0.003 & $\begin{array}{c}0.774 \\
(0.353-1.697)\end{array}$ & 0.522 \\
\hline $\begin{array}{l}\text { Vascular invasion } \\
\text { (yes vs. no) }\end{array}$ & $<0.001$ & $\begin{array}{c}3.756 \\
(1.037-13.606)\end{array}$ & 0.044 & $<0.001$ & $\begin{array}{c}2.609 \\
(1.005-6.772)\end{array}$ & 0.049 \\
\hline $\begin{array}{l}\text { OCT4 } \\
\text { (high vs. low) }\end{array}$ & 0.023 & $\begin{array}{c}1.890 \\
(0.687-5.201)\end{array}$ & 0.218 & 0.018 & $\begin{array}{c}1.503 \\
(0.663-3.407)\end{array}$ & 0.329 \\
\hline
\end{tabular}

Univariate analysis, Kaplan-Meier method; multivariate analysis, Cox proportional hazards regression model. HCC, hepatocellular carcinoma; OS, overall survival; 95\% CI, 95\% confidence interval; RFS, recurrence-free survival; HR, hazard ratio; AFP, $\alpha$-fetoprotein; NA, not adopted. 


\section{Discussion}

Despite the significant improvements in early diagnosis and treatment strategies for hepatocellular carcinoma (HCC) in recent years, postoperative recurrence and metastasis occur frequently, and the survival time and prognosis of HCC patients remain unsatisfactory (27). Therefore, novel treatment modalities and sensitive prognostic markers that can decrease the mortality rate of HCC are required. HCC is a complex and heterogeneous tumor with multiple genetic aberrations. Recent research revealed that accumulation of genetic and epigenetic changes leads to the clonal selection of cancer cells harboring malignant behavior potential. Aberrant expression of cancer-related genes is one of the hallmarks of cancer cells and plays a key role in hepatocarcinogenesis (28).

Oct4 is a transcription factor that has been reported to play a vital role in pluripotency maintenance of embryonic cells and tumor cells. Accumulating studies have suggested that Oct4 is indispensable for the development of drug resistance in prostate and liver cancer $(5,6)$. According to these studies and our previous study, we hypothesized that Oct4 may be implicated in hepatocarcinogenesis and malignant progression of HCC cells. First, we analyzed Oct 4 mRNA and protein expression in HCC tissues and cell lines. Our results revealed that Oct4 expression at the mRNA and protein level was significantly higher in HCC tissues compared with that in the corresponding non-malignant liver tissues (Fig. 1A and B). The results from the HCC cell lines were consistent with those from the clinical samples (Fig. 1C and D).

Furthermore, Oct4-shRNA was used in our study to investigate its effects on the biological behavior of HCC cells. The results indicated that downregulation of Oct4 expression in HCC inhibited cell viability and mobility in vitro (Fig. 2). Latest research has demonstrated that Oct4 may be detected in a number of solid tumors, including HCC, and has a major effect on patient prognosis (7-13). The biological function of Oct4 may regulate several signaling pathways, such as the $\mathrm{Wnt} / \beta$-catenin, TGF- $\beta /$ Smad, JAK/STAT and survivin/STAT3 signaling pathways $(25,29,30)$. Upon examination of the expression of signaling pathway-related proteins in clinical samples, we observed that the protein expression of survivin and phosphorylated STAT3 was increased, which was associated with Oct4 overexpression (Fig. 4). Western blotting results and cellular immunofluorescence analysis revealed that downregulating Oct4 expression decreased the expression of survivin and the phosphorylation of STAT3 in HCC cells, which were consistent with the results from clinical samples (Fig. 3). Our data revealed that silencing Oct4 exerted a stronger inhibitory effect on HCC cell viability and mobility in vitro. Furthermore, we observed that the involvement of Oct4 in the malignant progression of HCC cells may be through the survivin/STAT3 pathway.

Next, to determine the clinical significance of Oct 4 in HCC patients, we analyzed the association of the expression of Oct 4 with surgical outcome and clinicopathological characteristics. Our data revealed that patients with high Oct4 expression had a worse prognosis compared with those with low Oct4 expression. When comparing the two groups, patients with
Oct4-high HCC exhibited shorter overall and recurrence-free survival time (Fig. 5). In addition, increased expression of Oct4 in HCC patients was found to be significantly associated with vascular invasion $(\mathrm{P}=0.010)$, TNM stage $(\mathrm{P}=0.029)$ and tumor size $(\mathrm{P}=0.031)$. Multivariate and univariate analyses revealed that the overexpression of Oct 4 was found to be associated with patient prognosis, although not as significantly as advanced TNM stage and vascular invasion (Table III). In subsequent studies, we aim to expand the sample size to confirm this result.

The present study suggested that aberrant expression of Oct4 was crucial for the viability, migration and invasion of HCC cells, possibly through the survivin/STAT3 signaling pathway. The clinical findings revealed that overexpression of Oct 4 was associated with poor patient prognosis, and Oct4 was considered as an independent factor for predicting overall survival time. These results revealed that Oct4 may be promising as a novel therapeutic target for HCC. However, the molecular mechanisms underlying the function of Oct 4 in the survivin/STAT3 signaling pathway remain to be fully understood. Further studies are required to elucidate the genetic characteristics of Oct 4 and its potential as a target in anti-HCC therapy.

\section{Acknowledgements}

Not applicable.

\section{Funding}

No funding was received.

\section{Availability of data and materials}

The datasets used during the present study are available from the corresponding author upon reasonable request.

\section{Authors' contributions}

GW, QG and GS conceived and designed the experiments; GW and HZ performed the experiments; ZG analyzed the data; GW and GS wrote the study. All authors read and approved the manuscript and agree to be accountable for all aspects of the research in ensuring that the accuracy or integrity of any part of the work are appropriately investigated and resolved.

\section{Ethics approval and consent to participate}

The study protocol was approved by the Ethics Committee of Wujiang No. 1 People's Hospital and all patients signed a written informed consent form.

\section{Patient consent for publication}

Not applicable.

\section{Competing interests}

The authors declare that they have no competing interests. 


\section{References}

1. Forner A, Llovet JM and Bruix J: Hepatocellular carcinoma. Lancet 379: 1245-1255, 2012.

2. Su CQ: Survivin in survival of hepatocellular carcinoma. Cancer Lett 379: 184-190, 2016.

3. Cherepanova OA, Gomez D, Shankman LS, Swiatlowska P, Williams J, Sarmento OF, Alencar GF, Hess DL, Bevard MH, Greene ES, et al: Activation of the pluripotency factor OCT4 in smooth muscle cells is atheroprotective. Nat Med 22: 657-665, 2016.

4. Hu T, Liu S, Breiter DR, Wang F, Tang Y and Sun S: Octamer 4 small interfering RNA results in cancer stem cell-like cell apoptosis. Cancer Res 68: 6533-6540, 2008.

5. Wang XQ, Ongkeko WM, Chen L, Yang ZF, Lu P, Chen KK, Lopez JP, Poon RT and Fan ST: Octamer 4 (Oct4) mediates chemotherapeutic drug resistance in liver cancer cells through a potential Oct4-AKT-ATP-binding cassette G2 pathway. Hepatology 52: 528-539, 2010.

6. Linn DE, Yang X, Sun F, Xie Y, Chen H, Jiang R, Chen H, Chumsri S, Burger AM and Qiu Y: A role for OCT4 in tumor initiation of drug-resistant prostate cancer cells. Genes Cancer 1: 908-916, 2010

7. Ezeh UI, Turek PJ, Reijo RA and Clark AT: Human embryonic stem cell genes OCT4, NANOG, STELLAR, and GDF3 are expressed in both seminoma and breast carcinoma. Cancer 104: 2255-2265, 2005.

8. Gu G, Yuan J, Wills M and Kasper S: Prostate cancer cells with stem cell characteristics reconstitute the original human tumor in vivo. Cancer Res 67: 4807-4815, 2007.

9. Chen YC, Hsu HS, Chen YW, Tsai TH, How CK, Wang CY, Hung SC, Chang YL, Tsai ML, Lee YY, et al: Oct-4 expression maintained cancer stem-like properties in lung cancer-derived CD133-positive cells. PLoS One 3: e2637, 2008.

10. Atlasi Y, Mowla SJ, Ziaee SA and Bahrami AR: OCT-4, an embryonic stem cell marker, is highly expressed in bladder cancer. Int J Cancer 120: 1598-1602, 2007.

11. Chiou SH, Yu CC, Huang CY, Lin SC, Liu CJ, Tsai TH, Chou SH, Chien CS, Ku HH and Lo JF: Positive correlations of Oct-4 and Nanog in oral cancer stem-like cells and high-grade oral squamous cell carcinoma. Clin Cancer Res 14: 4085-4095, 2008.

12. Chen Z, Xu WR, Qian H, Zhu W, Bu XF, Wang S, Yan YM, Mao F, Gu HB, Cao HL, et al: Oct4, a novel marker for human gastric cancer. J Surg Oncol 99: 414-419, 2009.

13. Zhou X, Huang GR and Hu P: Over-expression of Oct4 in human esophageal squamous cell carcinoma. Mol Cells 32: 39-45, 2011.

14. Zhang R, Jin S, Rao W, Song F, Yin Q, Wang Y, Wang L, Xi Y, Zhang X, Wang M, et al: OVA12, a novel tumor antigen, promotes cancer cell growth and inhibits 5-fluorouracil-induced apoptosis. Cancer Lett 357: 141-151, 2015.

15. Athanasoula KCh, Gogas H, Polonifi K, Vaiopoulos AG, Polyzos A and Mantzourani M: Survivin beyond physiology: Orchestration of multistep carcinogenesis and therapeutic potentials. Cancer Lett 347: 175-182, 2014.
16. Salzano G, Riehle R, Navarro G, Perche F, De Rosa G and Torchilin VP: Polymeric micelles containing reversibly phospholipid-modified anti-survivin siRNA: A promising strategy to overcome drug resistance in cancer. Cancer Lett 343: 224-231, 2014.

17. Wang J, Li Z, Lin Z, Zhao B, Wang Y, Peng R, Wang M, Lu C, Shi G and Shen Y: 17-DMCHAG, a new geldanamycin derivative, inhibits prostate cancer cells through Hsp90 inhibition and survivin downregulation. Cancer Lett 362: 83-96, 2015.

18. Kanda N, Seno H, Konda Y, Marusawa H, Kanai M, Nakajima T, Kawashima T, Nanakin A, Sawabu T, Uenoyama Y, et al: STAT3 is constitutively activated and supports cell survival in association with survivin expression in gastric cancer cells. Oncogene 23: 4921-4929, 2004

19. Gritsko T, Williams A, Turkson J, Kaneko S, Bowman T, Huang M, Nam S, Eweis I, Diaz N, Sullivan D, et al: Persistent activation of stat 3 signaling induces survivin gene expression and confers resistance to apoptosis in human breast cancer cells. Clin Cancer Res 12: 11-19, 2006.

20. Glienke W, Hausmann E and Bergmann L: Downregulation of STAT3 signaling induces apoptosis but also promotes anti-apoptotic gene expression in human pancreatic cancer cell lines. Tumour Biol 32: 493-500, 2011.

21. Zhao C, Li H, Lin HJ, Yang S, Lin J and Liang G: Feedback activation of STAT3 as a cancer drug-resistance mechanism. Trends Pharmacol Sci 37: 47-61, 2016.

22. Zeng R, Tang Y, Zhou H, Liu Y, Huang J, Li L, Liu W, Feng Y, Zhou Y, Chen T, et al: STAT3 mediates multidrug resistance of Burkitt lymphoma cells by promoting antioxidant feedback. Biochem Biophys Res Commun 488: 182-188, 2017.

23. Huang S, Chen M, Shen Y, Shen W, Guo H, Gao Q and Zou X: Inhibition of activated Stat 3 reverses drug resistance to chemotherapeutic agents in gastric cancer cells. Cancer Lett 315: 198-205, 2012.

24. Nagaraj NS, Washington MK and Merchant NB: Combined blockade of Src kinase and epidermal growth factor receptor with gemcitabine overcomes STAT3-mediated resistance of inhibition of pancreatic tumor growth. Clin Cancer Res 17: 483-493, 2011.

25. Guo Y, Mantel C, Hromas RA and Broxmeyer HE: Oct-4 is critical for survival/antiapoptosis of murine embryonic stem cells subjected to stress: Effects associated with Stat3/survivin. Stem Cells 26: 30-34, 2008

26. Friedrichs K, Gluba S, Eidtmann $\mathrm{H}$ and Jonat W: Overexpression of p53 and prognosis in breast cancer. Cancer 72: 3641-3647, 1993.

27. Bruix J, Gores GJ and Mazzaferro V: Hepatocellular carcinoma: Clinical frontiers and perspectives. Gut 63: 844-855, 2014.

28. Umeda S, Kanda $M$ and Kodera $Y$ : Emerging evidence of molecular biomarkers in hepatocellular carcinoma. Histol Histopathol 33: 343-355, 2018.

29. Yuan F, Zhou W, Zou C, Zhang Z, Hu H, Dai Z and Zhang Y: Expression of Oct4 in HCC and modulation to wnt $/ \beta$-catenin and TGF- $\beta$ signal pathways. Mol Cell Biochem 343: 155-162, 2010.

30. Lee TI, Jenner RG, Boyer LA, Guenther MG, Levine SS, Kumar RM, Chevalier B, Johnstone SE, Cole MF, Isono K, et al: Control of developmental regulators by Polycomb in human embryonic stem cells. Cell 125: 301-313, 2006 